\title{
Falkenau:
}

\section{a vida póstuma dos arquivos}

//I/I/I/I/I/I/I/I Anita Leandro

ECO - UFRJ 
Resumo Quarenta e três anos depois do fim da Segunda guerra mundial, Samuel Fuller vê as imagens que registrou durante a liberação do último campo de concentração. Em seu filme, Falkenau, visão do impossivel (1988), Emil Weiss capta a emoção de Fuller na descoberta de marcas ainda vivas do passado, sedimentadas nos arquivos e nos lugares históricos.

\section{Palavras-chave}

montagem de arquivos, testemunho, cinema e história

\section{Abstract}

Forty-three years after the Second World War, Samuel Fuller regards the images that he filmed during the liberation of the last concentration camp. In Falkenau, vision de l'impossible (1988), Emil Weiss captures Fuller's emotion in front of the living marks of the past they find out at the archives and historic sites.

\section{Key-words}

assembly of archives, testimony, cinema and history 
Ao clamor das imagens do passado por reconhecimento, o cinema responde, predominantemente, com a montagem, etapa privilegiada da realização em seu trabalho com os arquivos e com o tempo. O que sobressai de documentários históricos como O fundo do ar é vermelho, de Chris Marker (1977), Oh! Uomo (2004), de Yervant Gianikian e Angela Ricci Lucchi ou História(s) do cinema (19881998), de Jean-Luc Godard, inteiramente apoiados na retomada de imagens de arquivo, é a exploração de um potencial memorialista da montagem, ou seja, sua capacidade de atualizar o passado. $\mathrm{O}$ congelamento da imagem, a repetição de certos planos, a sobreposição de outros, a interrupção do fluxo narrativo, a substituição da imagem por uma tela preta ou branca, a variação de velocidade do movimento, são alguns dos inúmeros procedimentos de montagem utilizados nesses filmes no tratamento visual e sonoro de questões históricas. Com a montagem de arquivo, o cinema renovou a arte da citação, do fragmento e da ruptura narrativa. A superposição de imagens revelou o caráter estratigráfico do arquivo, Godard sendo, talvez, o grande ensaísta desse tipo de composição. O reenquadramento no interior do fotograma e o slow motion, como fazem hoje os Gianikian, trouxeram à superfície das imagens o gesto de nossos 
antepassados, o detalhe até então imperceptível, fazendo brilhar o cristal de tempo histórico sobre o qual Deleuze tanto insistiu (Deleuze, 1985, p. 93). A montagem cinematográfica desdobrou os arquivos sonoros e visuais do século XX e organizou-os, numa verdadeira atividade historiadora, um pouco como Foucault o fez com os arquivos das instituições, se servindo, aliás, de uma terminologia corrente no cinema. ${ }^{1}$

Mas o tratamento dos arquivos no cinema não se limita à montagem. Ele coloca também uma questão de mise en scène, que amplia a noção de arquivo e exige uma abordagem diferenciada do vestígio da História já no momento das filmagens. Ao retornar aos lugares históricos, como acontece, por exemplo, nos filmes de Jean-Marie Straub e Danièle Huillet, ou ao trazer as imagens de arquivo para a frente das câmeras, junto com o personagem, como em alguns retratos de cineastas de André Labarthe, a mise en scène se antecipa à montagem e atribui às marcas do passado - imagem, monumento, ruína, texto - um lugar privilegiado no presente, da mesma forma que a fala de uma testemunha. Define-se, assim, um compartilhamento do espaço que põe num mesmo patamar o discurso do arquivo e o relato da pessoa filmada. Graças a essa igualdade de tratamento, uma cumplicidade se estabelece entre imagem e som, entre documento e palavra viva, enfim, entre passado e presente. Abordados como contemporâneos um do outro, arquivo e testemunha, ambos sobreviventes da História, participam em igualdade de condições de um esforço comum de compreensão do passado. Falkenau, visão do impossível (EMIL WEISS, 1988) é um filme que trabalha nesse sentido, reunindo num mesmo destino histórico a fala de Samuel Fuller, as imagens rodadas por ele durante a liberação do campo de concentração de Falkenau em 1945 e imagens recentes dos lugares onde o cineasta americano combateu. O método de associação de uma palavra viva aos documentos da guerra dá uma nova chance ao passado e cria, no momento das filmagens, as condições para que as imagens de arquivo e os monumentos históricos tenham o direito à vida póstuma, às sobrevivências de que fala Aby Warburg (WARBURG, 2003a e 2003b). ${ }^{2}$

O documentário de Emil Weiss retoma, na íntegra, os $21 \mathrm{mi-}$ nutos de imagens rodadas por Fuller, quando ele ainda não imaginava que seria, alguns anos depois, um dos maiores cineastas de Hollywood. Fuller tinha cerca de 30 anos de idade e trabalhava
1. Entre as novas categorias históricas utilizadas por Foucault para compreender os arquivos estão a serialização, a descontinuidade e, principalmente, a decupagem (Foucault, 1969, p. 14.). Tanto no cinema quanto na História, a decupagem remete ao recorte espacial que determina a relação da mise en scène ou da montagem com o tempo. O método estratigráfico de Foucault decupa os arquivos, da mesma forma que o fazem os grandes ensaístas contemporâneos da montagem.

2. O historiador da arte alemão Aby Warburg viu no conjunto das imagens produzidas ao longo dos séculos uma real capacidade de conservação da memória, da mesma forma que a matéria orgânica. Sem ater-se a fronteiras geográficas ou a critérios cronológicos, como faz a história da arte tradicional, ele aproximou imagens de diferentes formatos, épocas e civilizações e pôde constatar que um mesmo gesto humano, um mesmo Pathosformel as percorria, como um abalo sísmico imperceptível, mas permanente, transmitido através dos tempos. A abordagem antropológica de Warburg descortina para o século XX uma verdadeira história de fantasmas, justapondo culturas tão distantes umas das outras como a da Renascença e a dos pueblos do Novo México (Warburg, 2003). Esse processo de transmissão, que ele chamou de Nachleben, é traduzido por Agamben como a vida póstuma das imagens (Agamben, 1998). Didi-Huberman, outro estudioso importante do método warburguiano, fala de sobrevivência (DIDI-HUBERMAN, 2002). 
como repórter de polícia, quando foi convocado para servir como soldado na primeira divisão de infantaria norte-americana, a célebre Big Red One, à qual ele dedicaria, posteriormente, um filme histórico e autobiográfico (The Big Red One, 1980). Quando ainda estava na Tunísia, em 1942, Fuller recebera de sua mãe uma câmera Bell \& Howell de 16 milímetros, que atravessaria os combates na África do Norte (1942), na Sicília (1943) e na Normandia (1944), sem nunca ser utilizada, apesar de sua leveza e praticidade. Em maio de 1945, ao chegar em Falkenau, na região dos Sudetos, fronteira tcheco-polononesa-alemã, de forte presença alemã, a Big Red One, já com muitas baixas, faz o seu último combate e liberta o campo de concentração que ficava na entrada da cidade. Os aliados enfrentam a resistência dos habitantes locais em reconhecer a existência do genocídio. É aí, então, que o comandante da tropa, capitão Kimbel Richmond, percebe a utilidade das imagens e pede a Fuller para filmar o ritual fúnebre dos milhares de mortos que apodreciam no necrotério do campo. Com essas imagens, Fuller produziria, sem saber, um documento histórico único para a posteridade, registrando um fato inusitado na abertura dos campos de concentração: a preparação, por parte de civis negacionistas, de um enterro para os prisioneiros mortos.

\section{Diante das imagens}

O filme de Emil Weiss dura 52 minutos e grande parte das sequências se passa dentro de uma sala de projeção com um único espectador, Samuel Fuller. Sentado numa cadeira de diretor, de frente para a tela e, em alguns momentos, de costas para a câmera, Fuller assiste às imagens que filmou em 1945. Ele comenta cada plano, buscando na memória elementos que lhe permitam restituir os fatos em sua complexidade. O face-à-face da testemunha da História com os arquivos vai suscitar um depoimento revelador sobre a persistência do passado no presente. Fuller relembra o que aconteceu e descobre nas imagens elementos que outrora escaparam a sua percepção, como as colinas que circundam o campo, por exemplo, e de onde os moradores de Falkenau podiam perfeitamente ver os prisioneiros.

Seu discurso é elaborado a partir do que as imagens revelam, da visão do impossível que elas proporcionam, como anuncia o sub-tí- 
tulo do filme. Diretamente associada aos arquivos, a fala de Samuel Fuller oferecerá ao espectador uma visão daquilo cuja ressurreição é, por natureza, impossível, ou seja, o passado. E dado o caráter intolerável e inacreditável do horror que essas imagens revelam, o passado ressurge como algo duplamente impossível. Fuller parece espantado diante das imagens dos acontecimentos terríveis que sua câmera amadora registrou. A mise en scène justapõe o silêncio eloquente das cenas mudas, em preto e branco, ao murmúrio de uma palavra viva que, embora filmada no presente, a cores, transmite em sua formulação o sentimento de que pertence ao passado. A própria flexão da voz traduz uma intimidade com os mortos, um luto assimilado. Fuller é um sobrevivente da guerra, que lutou em todas as grandes batalhas da qual participou a Big Red One. Ele faz parte do grupo reduzido de seis soldados de sua divisão que chegaram vivos a Falkenau, último campo a ser liberado. É por isso que a mediação das imagens dispensa, aqui, o sistema tradicional de pergunta e resposta. A relação com os arquivos permite a Fuller vivenciar uma experiência interior, refratária ao discurso, ao saber adquirido (BATAILLE, 2009, p. 25). Em vez do enunciado sobre o passado, é o próprio passado que se apresenta nesse encontro com as imagens, o que dele sobrevive e que ainda é possível atualizar. Do diálogo de Fuller com os arquivos nasce um testemunho inesperado sobre a persistência da experiência da guerra no presente: ao mesmo tempo em que faz sua anamnèse, ele religa as imagens de Falkenau a acontecimentos atuais, atribuindo aos documentos de arquivo uma contemporaneidade inquietante.

Enquanto a projeção avança, Fuller conta a Emil Weiss como tudo aconteceu. Os habitantes de Falkenau insistiam no desconhecimento das atrocidades cometidas dentro do campo de concentração, situado, no entanto, ao lado de suas casas. A paz tinha sido assinada no dia anterior, 8 de maio, e se os aliados matassem alguém, por maior que fosse sua participação no genocídio, isso seria considerado crime. O capitão Richmond se contenta, então, em dar uma lição aos que negavam a evidência e escolhe entre as elites locais uma dezena de homens - juízes, banqueiros, empresários aos quais ordena que retirem do necrotério todos os mortos que ali se encontravam, empilhados e nus. As imagens mostram as pessoas mais importantes da cidade vestindo os corpos esqueléticos e desfigurados dos prisioneiros. A câmera, no meio da cena, insiste nos 
3. Todas as citações entre aspas sem referência bibliográfica são transcrições dos depoimentos de Samuel Fuller no filme.

4. Num artigo em que analisa Shoah, de Claude Lanzmann, Sánchez Biosca lembra que os fotógrafos e cineastas independientes que cobriram a abertura dos campos de concentração tinham todos esse cuidado de mostrar, sem nenhum corte, a contiguidade espacial dos visitantes e dos cadáveres amontonados, de forma que a imagem pudesse servir como um testemunho incontestável (Sánchez Biosca, 2001, p. 284). detalhes - rostos cadavéricos, mãos descarnadas, pés descalços como se o plano aproximado pudesse atribuir alguma identidade àqueles mortos de nacionalidade ignorada, vindos de mais de dez países diferentes e que agora iriam para uma vala comum. Em meio ao mau cheiro de carne gangrenada, como relembra Fuller, os representantes da alta sociedade de Falkenau realizam, sem protestar, a difícil tarefa. "A tensão era inimaginável”, diz Fuller. "Estávamos num barril de pólvora. Se um único homem tivesse se atrevido a contestar, teria sido um drama". ${ }^{3}$

Esse é o único filme conhecido até hoje de abertura dos campos de concentração em que se vê civis cumprindo rituais fúnebres de preparação dos mortos para o enterro. Eles pegam roupas, lençóis, toalhas, tudo o que encontram, e vestem os cadáveres cuidadosamente, "como uma mãe que veste um filho", compara Fuller diante das imagens da preparação dos corpos. Imóveis e silenciosos, os sobreviventes do campo de concentração assistem ao trágico espetáculo. Sem tripé, uma panorâmica de $360^{\circ}$ percorre o espaço em plano sequência, mostrando os prisioneiros, os soldados, a preparação do enterro e a cidade vizinha ao campo. Fuller explica o que queria exatamente com essa imagem: "É um plano sem cortes, uma única tomada, sem montagem. Eu apenas fiz uma panorâmica, para mostrar o quanto o campo era próximo. Eu não podia cortar."4 Ao ver essas imagens pela primeira vez, depois de tanto tempo, ele se surpreende ainda com a revelação de um detalhe importante. "As crianças brincando, subindo e descendo as colinas, podiam ver todos os prisioneiros. Eu nunca tinha pensado nisso antes". Fuller continua sua descrição do conteúdo das cenas. Um oficial russo, médico, reúne os prisioneiros e faz um pronunciamento macabro: alguns deles sofreram tanto de mal nutrição que lhes será impossível sobreviver; um segundo grupo, com doenças contagiosas, deve permanecer na prisão. "Foi uma provação para todos. Eu tinha a vantagem de estar ocupado com meu filme. Os outros tinham que olhar".

Ao final dos preparativos para o enterro, o capitão obriga os civis a levarem os mortos ao cemitério local. "O cheiro piora. Agora começa a partida do campo e o início do último êxodo". Talvez devido ao compartilhamento de um mesmo espaço com as imagens, Fuller descreve os fatos no presente, como se estivesse realmente revivendo a experiência. O cortejo fúnebre segue a pé e os homens de Falkenau empurram e puxam as pesadas carroças que 
levam os mortos. Alguns moradores saem às ruas para ver a passagem do enterro e Fuller chama a atenção para a imagem do capitão Richmond solicitando a um deles que retire o chapéu. Era preciso que os prisioneiros deixassem o mundo com uma certa dignidade e que os habitantes de Falkenau sentissem vergonha pela conivência com a tragédia que acabara de acontecer ao lado de suas casas. $\mathrm{O}$ comentário de Fuller penetra nas imagens, traduzindo o conteúdo de cada cena, o sentido de cada gesto. Antes mudas, as imagens são agora habitadas pelo vigor de sua fala e do timbre de sua voz.

$\mathrm{Na}$ medida em que as imagens vão sendo projetadas, na ordem em que foram filmadas e sem supressão de planos, Fuller improvisa seu depoimento, comunicando uma memória do que ficou registrado nas imagens. No cemitério, um jovem louro de calças curtas, um alemão, aparentemente, arruma os cadáveres dentro da grande vala comum. Ele cruza as mãos de cada morto sobre o peito e cobre todos com um grande lençol branco. Esta imagem suscita em Fuller uma fala contundente sobre a persistência do racismo nos dias atuais, reflexão que pontuará todo o filme, como um alerta. "Hoje ainda tem gente para dizer, como Le Pen, que tudo isso foi apenas um detalhe”. Ele evoca o neonazismo francês, mas também norte-americano. "Nos Estados Unidos, alguns pretendem que o genocídio é um mito, que não houve nem mil judeus mortos, que ninguém foi torturado, assassinado, condenado a morrer de fome, gasificado ou cremado, morto ou vivo". Diante do recrudescimento do racismo, ele vê na imagem uma importante aliada. "Espero que os nazistas de hoje pensarão duas vezes antes de negar o irrefutável. E quando eu digo nazista, é qualquer um que nega ou que perdoa os crimes nazistas ou esses americanos que negam a existência dos campos de concentração". Assim como o racismo, a guerra também não acabou. Ela apenas se deslocou geograficamente. "Hoje é preciso ir à Nicarágua, ao Afeganistão. Estas coisas continuam acontecendo nos dias atuais. Civis são mortos cada vez que cai uma bomba”. As imagens são ouvidas, interpeladas e atualizadas por Fuller como um problema do presente, e não apenas do passado. Jacques Derrida, que havia diagnosticado um verdadeiro "mal de arquivo" em nossas sociedades, se referindo a situações de dissimulação, de destruição, de interdição, de manipulação e até mesmo de recalque de arquivos que marcaram os desastres do final do último milênio, diz que o arquivo, para escapar a esses sintomas contemporâneos, precisa de um 
5. No início da Nouvelle Vague, a revista Cahiers du cinéma busca reabilitar a imagem de Fuller. Em

1959, Luc Mullet sugere que a questão ética, na obra fulleriana, já está prevista na própria forma: “a moral é um problema de travelling”, diz ele (Mullet, 1959). Em seguida, a fórmula é invertida por Jean-Luc Godard, que insiste na primazia da escolha ética em relação à escolha estética: "o travelling é um problema de moral" (Godard, 1959). A reflexão sobre a base moral da linguagem cinematográfica já se encontrava no centro das preocupações editoriais do Cahiers desde os seus primeiros números, com os artigos de Bazin.

Antoine de Baecque, que referese, em seu último livro, a algumas

passagens de Falkenau, visão do impossivel, retoma aspectos do debate Mullet-Godard ao atualizar a discussão sobre a representação da Shoah no cinema (De Baecque, 2008, p. 100 e 143). lugar exterior que o atualize (DERRIDA, 1995). No documentário, esse lugar exterior é a palavra, a experiência viva da fala, que nasce no presente das filmagens, dando aos arquivos uma nova chance.

E se, aqui, a pessoa filmada aparece como porta-voz solidária de um arquivo sem som, por outro lado as imagens também testemunham no lugar e a favor do próprio Fuller. Em sua carreira de produtor e diretor de cinema, iniciada depois da guerra, ele foi, às vezes, tachado de "anti-comunista", devido ao conteúdo de alguns de seus filmes. ${ }^{5}$ As imagens de Falkenau resistem, de uma certa maneira, a essas acusações. $\mathrm{O}$ combate ao negacionismo assumido pela longa panorâmica que religa o interior do campo ao seu exterior, só é possível porque há uma postura ética do soldado Fuller diante dos horrores da guerra. Embora amadora, sua câmera adota um ponto de vista que invalida a afirmação dos moradores da cidade de que desconheciam o que se passava dentro da prisão. Num único plano, a geopolítica do espaço de Fuller inscreve o campo de concentração numa paisagem urbana que assistiu em silêncio ao genocídio. Bem perto dos muros da prisão, há ruas com igreja e casas, algumas com vista para o interior do campo. Seu plano revela essa proximidade incriminadora. Muito antes de se tornar cineasta, Fuller já abordava a panorâmica como uma questão de moral. Uma ética do movimento de câmera já remete, nessa tomada única, às bases do estilo clássico de uma obra que exercerá, quinze anos mais tarde, forte influência nos cineastas da Nouvelle vague, Godard particularmente. A ligação que a panorâmica de Fuller estabelece entre dois espaços pretensamente separados produz, em 1945, uma prova do crime para os historiadores do futuro. As imagens arquivaram esse gesto de resistência que, hoje, reconcilia Samuel Fuller com seus contemporâneos. Se, meio século depois da guerra, os arquivos ainda participam do julgamento dos crimes da História, alertando os tempos atuais quanto ao neonazismo, é porque as imagens de Fuller se posicionaram eticamente, elas tomaram partido (DIDI-HUBERMAN, 2009).

O dispositivo de filmagem adotado por Weiss transpõe a soleira do discurso objetivo, da informação eficaz e da fala científica do especialista em História, predominantes no documentário baseado em arquivos. Num artigo sobre o conjunto de imagens de abertura dos campos, Didi-Huberman comenta os 21 minutos rodados por Fuller em Falkenau e se refere ao dispositivo adotado mais tarde por Emil Weiss nos seguintes termos: "São as próprias imagens que, 
embora totalmente mudas, interrogam a testemunha. Tomando a palavra, ela lhes dará a possibilidade de serem verdadeiramente olhadas, lidas, ou mesmo, ouvidas" (DIDI-HUBERMAN, 2006, p. 1035). As imagens do genocídio, visão do impossível, na definição de Fuller, comparecem em sua materialidade, expondo o vestígio histórico em sua própria incompletude. A força do arquivo parece estar, justamente, no murmúrio que nele ecoa e que a fala do entrevistado potencializa, comunicando uma fragilidade no discurso da História. O arquivo é uma reminiscência, uma palavra distante que interpela o presente. "Esses mortos, eu os guardei dentro de mim. É um pesadelo impossível. Nunca esquecerei”, diz Fuller. A descoberta do horror inenarrável do genocídio será, como se sabe, determinante para ele, orientando os grandes temas que nortearão sua obra: violência, loucura, prisão, tortura, guerra. Há nas cenas de Falkenau uma série de quatro imagens de mortos, em close, que elucidam certos aspectos da estilística fulleriana, sua forma de filmar o rosto dos atores. Os rostos pálidos dos mortos de Falkenau resplandescem numa moldura de escuridão e seus olhos, ainda abertos, fixam o infinito, o extra-campo. Há uma súplica silenciosa nesse claro-escuro, que nos atinge em cheio graças ao olhar demorado do soldado Fuller, à compaixão e ao respeito de sua imagem amadora pelos mortos. A questão do ponto de vista histórico situa-se além e aquém da estética e da técnica. Com esses rostos iluminados pelo sol de maio, Fuller constrói, como diria Daney sobre os Straub, um túmulo para o olho (Daney, 1996, p. 78). Num texto fortemente inspirado pela antropologia da imagem warburguiana, Didi-Hubermann diz algo semelhante, ao abordar o tema da abertura na história das imagens: "uma imagem pode ser muito mais do que uma vista longínqua projetada numa tela ou controlada pelo enquadramento de uma janela. Ela pode ser a visão precipitada de um espaço aberto onde cai nosso olhar”. É a circunspecção de um ponto de vista demasiadamente humano, muito mais do que um desejo de pintura da parte de Fuller, que nos coloca em estado de contemplação diante desses quatro planos de rostos petrificados.

O arquivo é, por definição, o que sobrou do passado, restos que se situam entre uma possibilidade e uma impossibilidade de dizer (Agamben, 2003, p. 156). Sua presença não é, então, suficiente para restituir o fato histórico. Mas ela desperta em Fuller sentimentos 
adormecidos de experiências vividas. O pesadelo impossível de que ele fala é a perspectiva interior de uma imagem que já foi por ele introjetada. A questão é de fundamental importância para o cinema e suscita entre entrevistador e entrevistado uma discussão que ocupa os últimos dez minutos do filme. Numa atitude moral próxima da de Claude Lanzmann, Emil Weiss quer convencer Samuel Fuller de que, no caso particular do universo concentracional, a imagem tem um limite a não ser ultrapassado, que é o da representação. Weiss comenta a passagem do livro autobiográfico de Robert Antelme, A espécie humana, em que o autor, prisioneiro num campo de concentração, ao mirar-se no espelho vê outra imagem que não a sua. A imagem da condição de homem lhe escapa e sua representação, para Weiss, é impossível. Romancista e roteirista, além de diretor, Fuller discorda, sustentando que tudo é possível no cinema de ficção e que, com um bom ator, se o queremos, conseguimos. "O ator tem que levar o público ao inferno com ele”. O obstáculo está, ele acredita, em como encontrar dinheiro para produzir um filme sobre os campos de concentração sem fazer nenhuma concessão. "Os produtores seriam todos indiretamente cúmplices do que aconteceu. Os bancos, os distribuidores teriam exigências".

Enquanto Fuller fala de seu processo de assimilação dos mortos, a montagem congela a imagem do primeiro punhado de terra caindo sobre os corpos envoltos em lençol branco, no fundo da vala. Há uma generosidade dos arquivos ao acolherem a fala da testemunha ou sua impossibilidade de testemunhar, ao se oferecerem como uma evidência dos fatos inenarráveis que ela tenta rememorar. Da mesma forma que há, também, no método de entrevista de Weiss, uma mão estendida aos arquivos, que ao final de contas, são apenas vestígios da História, nada mais que 21 minutos de imagens de um único campo de concentração, entre tantos outros. São os depoimentos de Fuller que apresentam esses arquivos como uma prova, como uma evidência da história (HARTOG, 2005). Aliás, Fuller retoma essa noção da historiografia ao responder a uma pergunta de seu entrevistador sobre como representar o impossível: "As imagens de arquivo ainda terão um valor daqui há mil anos, um valor de prova, como uma evidência. É por isso que eu amo o cinema. Ninguém mais pode mentir sobre o que acabou de ver". Fuller acreditava que tudo era possível com uma câmera, a partir do momento em que se tem o controle da produção e da distribuição. 


\section{Nos lugares da História}

A interpelação dos vestígios do passado, iniciada na sala de projeção, se prolonga nos lugares históricos que vão ser percorridos por Emil Weiss e Samuel Fuller. Além das ruínas de Falkenau, eles visitam o campo de Terezin, onde há documentos relativos ao genocídio, e vão também a Nuremberg. No grande portão de Terezin, debaixo da frase "o trabalho liberta", Fuller explica como a escravidão concentracionista alimentou a indústria da guerra e sustentou economicamente o projeto de extermínio. No interior da biblioteca de Terezin, Fuller mostra um mapa dos campos de concentração e documentos de contabilidade da indústria da morte. À maneira de um repórter, ele guia o espectador. A diferença em relação à reportagem é que, aqui, os fatos são relatados a partir do ponto de vista subjetivo, por alguém que viveu os acontecimentos narrados, o que estabelece um vínculo entre passado e presente. Imagens de arquivo já conhecidas, feitas por cinegrafistas alemães, são utilizadas nas sequências rodadas em Nuremberg. A visita à praça central da cidade autoriza a convocação de imagens de um desfile militar, em que Hitler se dirige à multidão. Fuller lembra que foi ali que nasceu a noção de "crime de guerra", em 1946, e sua fala nos dá acesso a imagens do processo de Nuremberg. Mais uma vez, passado e presente se justapõem na montagem, quando Fuller aparece na sala do processo, mostrando o lugar em que, na época do julgamento dos criminosos, havia uma tela para a projeção de imagens de genocídio durante o depoimento dos acusados.

Em Falkenau, uma lenta panorâmica vertical sobre o monumento ao fim da guerra mostra Samuel Fuller lendo uma longa lista de nomes de soldados mortos, precedida de um epitáfio, em inglês: "Aqui terminou a marcha vitoriosa da infantaria americana". Uma segunda panorâmica, igualmente calma, descortina as ruínas do campo, enquanto Fuller identifica os alicerces das antigas casas de pedras que beiravam a estrada. Mais adiante, numa construção com aberturas laterais, ficavam as metralhadoras alemãs que era preciso neutralizar. "Vou mostrar como foi", diz Fuller descendo uma colina. Apesar de sua idade avançada no momento em que é filmado por Weiss, ele corre, salta um obstáculo e se abaixa para pegar uma granada invisível, como se buscasse na reprodução de cada gesto, uma memória física, corporal, daquilo que viveu. "Corríamos 
beirando o muro, que ficava aqui, pulávamos, jogávamos a maldita granada e corríamos de novo". No momento em que ele mostra como arremessava as granadas, ouve-se uma explosão. A montagem antecipa a banda sonora de uma imagem de ficção que aparecerá logo depois: num raccord perfeito no gesto, um soldado de The Big Red One, o filme autobiográfico de Samuel Fuller, arremessa uma granada contra os alemães. "Foi assim que tomamos Falkenau". O raccord entre o documentário e a ficção, a necessidade de religar o passado ao presente, legitimam a participação de The Big Red One na restituição dos fatos.

Da mesma forma que sua mise-en-scène dos arquivos, a montagem de Weiss também mobiliza o potencial memorialista do cinema e, por meio do raccord, traz à superfície das imagens a solidariedade existente, mas nem sempre reconhecida, entre real e ficção. Embora sejam ficcionais e só apareçam a posteriori, na montagem, as imagens de The Big Red One, solicitadas pelo gesto de Samuel Fuller e pela própria paisagem, também testemunham. A precisão no gesto dos soldados e na reconstituição do cenário é o resultado de um roteiro escrito e encenado por um ex-combatente que viveu os fatos narrados. Já na abertura de Falkenau, visão do impossível, um prólogo sem comentários mostrava imagens de The Big Red One, no momento exato da tomada do campo de concentração pelos americanos. Vemos os soldados paralisados pela descoberta de sobreviventes esqueléticos e amedrontados, quando a voz de Fuller, no presente, vem romper o silêncio da cena de ficção. Ele evoca a insanidade da guerra e a impossibilidade, para quem não a tenha vivido, de compreender o que essa palavra quer dizer. Fuller conta que Falkenau superou em crueldade as coisas mais terríveis que tinha visto, os maiores pesadelos que vivenciara até então.

O raccord é a marca estilística das sequências rodadas nos lugares históricos. Após a imagem de arquivo dos sobreviventes de Falkenau, agachados, observando a retirada dos corpos do necrotério, a montagem corta para um plano atual de Fuller, no mesmo local: "Os prisioneiros estavam sentados no chão, assim". Ele se abaixa, fica de cócoras e continua: "Quando o primeiro corpo saiu, todos se levantaram ao mesmo tempo. Não havia todo esse mato". Weiss pensa sua mise en scène dos lugares históricos à luz das imagens de 45, cuja força ele busca potencializar em cada um de seus planos, reproduzindo os mesmos movimentos de câmera feitos 
outrora por Fuller e procurando, nas ruínas, algum vestígio daquilo que as imagens de arquivos preservaram.

Os lugares da História são interlocutores de Samuel Fuller. Eles mediam sua fala, da mesma forma que as imagens de arquivo. Como em S21, máquina de morte Khmer Vermelho (2003), de Rithy Panh, a paisagem do genocídio, a arquitetura e o documento são filmados como vestígios materiais do passado e testemunham ao lado do personagem. As paisagens abandonadas, com suas cercas cobertas de ervas, presenciaram tudo. As árvores arquivaram os gritos dos prisioneiros torturados e o que Weiss parece buscar com suas panorâmicas e raccords insistentes é o testemunho da natureza.

A participação do arquivo na filmagem, seja materialmente, como durante as projeções das imagens de 45, seja potencialmente, por meio do raccord entre documentário e ficção, entre passado e presente, cria para o cinema uma possibilidade de interferir nos processos de elaboração da memória e de exercer uma atividade historiadora. Fuller resgata suas lembranças da guerra e formula uma narrativa da História a partir de seu ponto de vista. Em sua análise do tratamento de arquivos nos filmes de Guy Debord, Agamben já havia localizado na montagem o desenvolvimento de, pelo menos, dois procedimentos estilísticos, a interrupção e a repetição, relacionados, segundo ele, à função memorialista da imagem e ao seu "caráter eminentemente histórico" (AGAMBEN, 1998, p. 66). Com efeito, essas duas grandes possibilidades da montagem já eram apontadas nas teses benjaminianas da História como condições de possibilidade para que, além da rememoração, o presente proceda à reparação dos sofrimentos inacabados do passado (Benjamin, 1991, p. 339). O método de leitura dos arquivos e de elaboração da palavra colocado em prática no filme de Weiss realiza, de certa forma, o desejo frustrado do anjo da História de Benjamin de parar o progresso, enterrar os mortos, cuidar dos feridos e clarear as trevas do presente com os ensinamentos do passado. Não é outro o procedimento de Fuller ao interromper a narrativa cronológica da história e religar as imagens de Falkeneau ao que se passa no mundo naquele exato momento. $\mathrm{O}$ vai-e-vem entre as imagens do passado e o presente das filmagens encoraja-o a fazer essa montagem associativa de idéias, aproximando, exatamente como no método de Warburg, acontecimentos distantes um do outro no tempo e no espaço, mas produzidos por um mesmo gesto humano que atravessa a História, no caso, o racismo. A inter- 
rupção, no cinema e em qualquer outra forma de escrita, reeduca o olhar habituado aos fluxos contínuos e comunica uma tomada de posição das imagens na guerra. Através da interrupção, mise en scène e montagem oferecem uma visão dos fatos não-linear, em profundidade, que torna possível uma arqueologia do olhar.

Além da interrupção, o filme de Emil Weiss introduz também a repetição como método de construção da narrativa da História: ver de novo imagens esquecidas, compartilhando um ritual à memória dos mortos; voltar em peregrinação ao lugar histórico e percorrê-lo novamente, buscando, na própria topografia do terreno alguma marca que permita atualizar o passado. Repetição também na reencenação de gestos perdidos ou recalcados ou quando o raccord identifica a ficção ao documentário, o presente ao passado. A fotografia de Emil Weiss também procede por repetição, com panorâmicas das ruínas que prolongam as imagens do campo traçadas quarenta anos antes por Fuller. Através da repetição, mise en scène e montagem comunicam a atualidade do gesto histórico, sua sobrevivência. Ela dá uma nova chance ao passado e insiste no fato de que ele ainda não passou.

\section{Vozes inaudiveis}

Ao retomar todos esses arquivos de diferentes registros e épocas, Emil Weiss faz uma escolha formal, mas também ética, que consiste em considerar a imagem como matéria viva, autônoma e singular, detentora de um discurso próprio, mesmo quando silenciosa e trêmula, como as imagens do jovem Fuller. A atitude de Weiss em relação aos arquivos se assemelha à do historiador que, diante da efemeridade das marcas deixadas pelo passado, aceita o desafio de produzir um discurso que organiza, como diz Michel de Certeau, uma "presença ausente" (DE CERTEAU, 1973, p. 9). "São apenas 21 minutos", insiste Fuller, "e dá para sentir o amadorismo". É nesse sentido que o filme de Weiss oferece ao arquivo a possibilidade de uma vida póstuma. Ele torna possível o impossível, mesmo que de maneira fugaz. Benjamin não dizia que a imagem do passado só nos aparece num lampejo?

Sem negar a importância do gesto de um cineasta como Claude Lanzmann, que em nome de impossibilidade de representar o ir- 
representável, recusa a utilização de imagens da Shoah em seus filmes, fazendo disso uma questão de princípios, a convocação dos arquivos no cinema não parece, no entanto, restringir-se a um problema de representação. É muito mais a uma questão de presença, de apresentação do arquivo que nos remete o método de Weiss. E, ao contrário do que uma certa crítica da ontologia da imagem poderia argumentar, como tem feito, de maneira precipitada, com a obra de Bazin, por exemplo, a vida póstuma dos arquivos, sua encarnação na fala de Samuel Fuller, não tem nenhuma relação com a doutrina cristã. Da mesma forma que a imagem aberta de DidiHubermann, para além dos limites da representação, os arquivos são um motivo, um motor do filme, e funcionam como um fantasma exploratório (DIDI-HUBERMAN, 2007, p. 31). A materialidade do arquivo em Falkenau, visão do impossivel produz, como vimos, um verdadeiro encontro entre o que resta dos campos de concentração e a fala de uma testemunha, criando, assim, a possibilidade de reconstituição de um "elo natural entre a palavra e a imagem" (Warburg, 2003b, p. 106). Abordada como um personagem que tem um discurso próprio, a imagem de arquivo reaparece como um problema atual: ela auxilia a pessoa filmada na elaboração de seu testemunho e, graças à memória armazenada que carrega, o presente pode ser compreendido à luz dos acontecimentos passados. É dessa forma que os arquivos interferem na qualidade da narrativa histórica singular que o cinema é capaz de organizar. Ao se colocar à escuta dos arquivos, Weiss restitui, como diria Warburg, o timbre das vozes inaudíveis do passado, as vozes dos mortos, vozes que ainda ecoam em milhares de documentos decifrados e ainda por decifrar. 


\section{Bibliografia}

AGAMBEN, Giorgio. Image et mémoire, Hoëbeke, 1998.

AGAMBEN, Giorgio. Ce qui reste d'Auschwitz. L'archive et le témoin. Homo Sacer III. Traduit de l'italien par Pierre Alferi. Paris: Editions Payot \& Rivages, 2003.

BATAILLE, Georges. L'experience intérieure. Paris: Gallimard, 2009 (1943 e 1954).

BENJAMIN, Walter. "Sur le concept d'histoire". In: Ecrits français. Paris: Gallimard, 1991.

DANEY, Serge. La Rampe. Paris: Cahiers du cinéma, 1996.

DE BAECQUE, Antoine. L'histoire-caméra. Paris: Gallimard, 2008.

DE CERTEAU, Michel. L'absent de l'histoire. Paris: Mame, 1973.

DELEUZE, Gilles. Image-temps. Paris: Éditions de Minuit, 1985.

DERRIDA, Jacques. Mal d'archive. Paris: Galilée, 1995.

DIDI-HUBERMANN, Georges. L'image survivante. Histoire de l'art et temps des fantômes selon Aby Warburg. Paris: Les Editions de Minuit, 2002.

DIDI-HUBERMANN, Georges. "Ouvrir les camps, fermer les yeux". In: Annales HSS, septembre-octobre, $\mathrm{n}^{\circ}$ 5, pp. 1011-1049, 2006.

DIDI-HUBERMANN, Georges. L'image ouverte. Paris: Gallimard, 2007.

DIDI-HUBERMANN, Georges. Quand les images prennent position. L'oeil de l'histoire I. Paris: Les Editions de Minuit, 2009.

FOUCAULT, Michel. Archéologie du savoir. Paris: Gallimard, 1969.

HARTOG, François. Evidence de l'histoire. Ce que voient les historiens. Paris: Editions de l'EHESS \& Gallimard.

MICHAUD, Philippe-Alain. Aby Warburg et l'image en mouvement. Paris: Macula, 1998.

SÁNCHEZ BIOSCA, Vicente. "Imágenes marcadas a fuego. Representación y memoria de la Shoah". In: Revista Brasileira de História. São Paulo, vol. 21, n 42, 2001, p. 283-302.

WARBURG, Aby. Le rituel du serpent. Art et antropologie. Traduit de l'allemand par Sibylle Muller. Paris: Macula, zooza.

WARBURG, Aby. Essais florentins. Traduit de l'allemand par Sibylle Muller. Paris: Klincksieck, 2003b. 